\title{
Innovations in Measuring Accessibility: Theoretical and Practical Perspectives
}

\author{
Helen Petrie, Chris Power \\ Department of Computer Science \\ University of York \\ York YO10 5DD \\ United Kingdom \\ +44 1904434336 \\ \{petrie,cpower\}@cs.york.ac.uk
}

\author{
Ray Adams \\ CIRCUA \\ School of Computing Science \\ Middlesex University \\ London NW4 4BT \\ United Kingdom \\ +442084115789
}

ray.adams@mdx.ac.uk

\author{
Faustina Hwang \\ School of Systems Engineering \\ University of Reading \\ Reading RG6 6AY \\ United Kingdom \\ +44 1183787668
}

f.hwang@reading.ac.uk

\author{
Carlos A. Velasco \\ Fraunhofer Institute of Applied \\ Information Technology \\ Sankt Augustin \\ Germany \\ +492241142609 \\ carlos.velasco@fit. \\ fraunhofer.de
}

\section{g.weber@hci-research.de}

\begin{abstract}
Recently, there has been an increased awareness in the general public, in government and in business that people with disabilities and older people have distinct needs and preferences that must be met in order for them to participate as equal members of environments incorporating information and communications technologies. With this increased awareness has come legislation and company policies stating the necessary provision of accessible systems for disabled and older people in all facets of society.

In order for these policies to be properly implemented there is a need to further understand accessibility and its impact on the people and systems around us. This workshop will focus on exploring the concept of accessibility and the boundaries of accessibility research. It is intended to bring together individuals working in disparate fields of research to improve the definition of accessibility and to refine our understanding of the as yet unaddressed barriers in the information society such as the impact of mobile technology and the aging population.
\end{abstract}

\section{Categories and Subject Descriptors}

H.5.2 [Information interfaces and presentation]: User interfaces - theories and methods.

\section{General Terms}

Human Factors.

\section{Keywords}

Accessibility, disabled people, older people, theory and methods.

\section{INTRODUCTION}

As we move towards the information and knowledge society, it is important to ensure that all citizens have access to the many emerging technological developments involved and are able enjoy the benefits from them. For example, the European Union in a series of policies (eEurope 2002, eEurope 2005, $\mathrm{i} 2020^{1}$ ) has stressed the importance of including people with disabilities and older people in the information society.

Part of the reason for this emphasis is the changing demographic make-up of European society. In Europe, Average life expectancy is now over 80 , and by 2020 around $25 \%$ of the population will be over 65 . This has two consequences for the information society. Firstly, the number of citizens who will potentially need specially adapted access to technology will increase rapidly in the near future. Secondly, with an aging population and fewer younger people to after their seniors and less-able members of society, we will need good technology for people to live as independently as possible.

Barriers to the information society reflect both system and user characteristics, and the interaction of these two sets of characteristics. It is becoming clear that accessibility is itself a complex concept and can be defined at a number of levels and from a number of perspectives. Therefore the concept of accessibility needs to be elaborated to exposes such complexity in ways that is useful to system designers, researchers and other stakeholders.

\footnotetext{
${ }^{1} \mathrm{http} / / /$ ec.europa.eu/information_society/eeurope/i2010/inclusion/
} 


\section{DEFINITIONS OF ACCESSIBILITY}

Accessibility, unlike usability, is a term for which there is not yet a generally accepted definition (Petrie and Kheir, 2007). It usually refers to the use of electronic systems, products or services (henceforth e-systems) by people with special needs, particularly those with disabilities and older people. ISO 9241171 [2] defines accessibility as:

"the usability of a product, service, environment or facility by people with the widest range of capabilities"

So this definition can be thought of as conceptualizing accessibility as simply usability for the maximum possible set of specified users accommodated; this fits within the universal design or design for all philosophy. However, accessibility is also used to refer to making e-products specifically usable by people with disabilities. For example, the Web Accessibility Initiative $(\mathrm{WAI})^{2}$, founded by the World Wide Web Consortium (W3C) to promote the accessibility of the Web defines web accessibility to mean:

"that people with disabilities can use the Web. More specifically, Web accessibility means that people with disabilities can perceive, understand, navigate, and interact with the Web (WAI, 2006)"

The WAI definition suggests that accessibility is a sub-set of usability (that accessibility is only concerned about people with disabilities), whereas the ISO suggests that usability is a sub-set of accessibility (that accessibility is concerned with the widest range of capabilities). However, for practical purposes, when discussing the development of e-systems for mainstream (i.e. non-disabled, younger) users and the problems that these users have with such systems, usability is the term used; whereas, when the development of e-systems for disabled and older users and the problems these users have with such systems, accessibility is the term used [3].

\section{WORKSHOP GOALS}

This workshop is intended to draw together experts from both research and industry to explore the definition of accessibility in the emerging information and knowledge society. The workshop will explore the following topics:

How is accessibility conceptualized in the modern information and knowledge society?

How can accessibility be quantified in specific applications (e.g. web, desktop applications) and in more general contexts?

What tools and techniques can be used for personalization of technology to particular users?

How can users and their devices, such as assistive technologies, be modelled to provide personalized services?

How can ambient intelligence be leveraged to provide accessible systems?

These, and many other questions remain open in the accessibility community. Indeed, many of these topics are fundamental to setting a unified direction for future research that will benefit disabled and older people.

\section{WORKSHOP PROCEDURE}

The programme committee has solicited papers from as many research and practitioner domains as possible in order to include a broad range of opinions and experiences. The papers that will be selected will be those that show a deep commitment to exploring the broader topics in accessibility, and in particular those that show interesting theoretical and practical approaches, case studies and user-based research that are committed to drawing out the nuances in the definitions used in accessibility research.

The format of the workshop will be designed to encourage collaboration between the participants and in particular to facilitate interactions between people in different fields of research and practice.

A set of proceedings will be provided at the beginning of the workshop in order to give the participants a common starting point for discussion. These proceedings will also be made available online prior to the workshop.

\section{WORKSHOP AGENDA}

The workshop will have several distinct stages of work:

Introductions: Introductions of participants.

Paper Sessions: Participants will be given the opportunity to present work submitted to the workshop.

Working Groups: After the presentations, the workshop will move into a set of sessions exploring topics of interest to the research and industrial communities. These topics are drawn from the original workshop goals, with each session linking together several related themes.

\section{WORKSHOP OUTPUTS}

A summary of discussions that occur during the workshop will be written and published through the workshop website. It is hoped that this workshop will produce a deeper understanding of accessibility and the issues surrounding its provision. It is expected that the networking activities that occur at this workshop will result in lasting partnerships between researchers and practitioners for purposes of pursuing new and interesting research in accessibility.

\section{REFERENCES}

[1] Petrie, H. and Kheir, O. (2007). The relationship between accessibility and usability of websites. Proceedings of CHI '07: ACM Annual Conference on Human Factors in Computing Systems. New York: ACM Press.

[2] International Standards Organization (2008). ISO 9241 171: Ergonomics of human-system interaction. Part 171: Guidance on software accessibility. Geneva: International Standards Organization.

[3] Petrie, H. and Bevan, N. (in press). The evaluation of accessibility, usability and user experience. In C. Stephanidis (Ed.), The Universal Access Handbook. CRC Press

\footnotetext{
2 www.w3c.org/WAI
} 